\title{
Cannabidiol has a unique effect on global brain activity: a pharmacological, functional MRI study in awake mice
}

\author{
Aymen H. Sadaka', Ana G. Ozuna', Richard J. Ortiz², Praveen Kulkarni ${ }^{1}$, Clare T. Johnson ${ }^{3}$, Heather B. Bradshaw ${ }^{3}$, \\ Bruce S. Cushing ${ }^{2}$, Ai-Ling Li ${ }^{3}$, Andrea G. Hohmann ${ }^{3,4}$ and Craig F. Ferris ${ }^{1,5,6^{*}}$ (D)
}

\begin{abstract}
Background: The phytocannabinoid cannabidiol (CBD) exhibits anxiolytic activity and has been promoted as a potential treatment for post-traumatic stress disorders. How does CBD interact with the brain to alter behavior? We hypothesized that CBD would produce a dose-dependent reduction in brain activity and functional coupling in neural circuitry associated with fear and defense.
\end{abstract}

Methods: During the scanning session awake mice were given vehicle or $\operatorname{CBD}(3,10$, or $30 \mathrm{mg} / \mathrm{kg}$ I.P.) and imaged for $10 \mathrm{~min}$ post treatment. Mice were also treated with the $10 \mathrm{mg} / \mathrm{kg}$ dose of CBD and imaged $1 \mathrm{~h}$ later for resting state BOLD functional connectivity (rsFC). Imaging data were registered to a 3D MRI mouse atlas providing site-specific information on 138 different brain areas. Blood samples were collected for CBD measurements.

Results: CBD produced a dose-dependent polarization of activation along the rostral-caudal axis of the brain. The olfactory bulb and prefrontal cortex showed an increase in positive BOLD whereas the brainstem and cerebellum showed a decrease in BOLD signal. This negative BOLD affected many areas connected to the ascending reticular activating system (ARAS). The ARAS was decoupled to much of the brain but was hyperconnected to the olfactory system and prefrontal cortex.

Conclusion: The CBD-induced decrease in ARAS activity is consistent with an emerging literature suggesting that CBD reduces autonomic arousal under conditions of emotional and physical stress.

Keywords: Tonic immobility, Behavioral arrest, Reticular activating system, Olfaction, $\mathrm{N}$-acylphosphatidylethanolamines-specific phospholipase D, PTSD, Negative BOLD

\section{Introduction}

CBD has anxiolytic properties, reducing the autonomic and emotional responses to stress and interfering with the consolidation and extinction of fearful memories [1], which has been associated with anxiety disorders [2], autism spectrum disorder [3], psychosis [4] and post-traumatic stress disorder [5]. It's potential as

\footnotetext{
*Correspondence: c.ferris@northeastern.edu

${ }^{6}$ Department of Psychology, Northeastern University, $125 \mathrm{NI}$ Hall, 360 Huntington Ave, Boston, MA 02115-5000, USA

Full list of author information is available at the end of the article
}

a therapeutic compound is emphasized by the fact that $\mathrm{CBD}$ is the primary active compound in the anti-epileptic drug, Epidiolex [6]. CBD has a complex pharmacology within the brain impacting multiple receptors by altering the lipidome, increasing and/or decreasing lipid mediators in specific brain areas [7], associated with dose, neurological condition and the environment. The primary targets for CBD given systemically are unknown. Non-invasive magnetic resonance imaging (MRI) using changes in BOLD (blood oxygen level dependent) signal has been used to detect the immediate increases and

c) The Author(s) 2021. This article is licensed under a Creative Commons Attribution 4.0 International License, which permits use, sharing, adaptation, distribution and reproduction in any medium or format, as long as you give appropriate credit to the original author(s) and the source, provide a link to the Creative Commons licence, and indicate if changes were made. The images or other third party material in this article are included in the article's Creative Commons licence, unless indicated otherwise in a credit line to the material. If material is not included in the article's Creative Commons licence and your intended use is not permitted by statutory regulation or exceeds the permitted use, you will need to obtain permission directly from the copyright holder. To view a copy of this licence, visit http://creativeco mmons.org/licenses/by/4.0/. The Creative Commons Public Domain Dedication waiver (http://creativecommons.org/publicdomain/ zero/1.0/) applies to the data made available in this article, unless otherwise stated in a credit line to the data. 
decreases in site-specific brain activity in response to various drugs [8-11]. The changes in BOLD signal are basically a proxy for increases and decreases in cerebral blood flow to areas of increased and decreased metabolic activity, respectively. Several studies in humans have used functional BOLD imaging to look at the neuroanatomy affected by treatment with CBD [12-19]. These studies looking at the effects of CBD have all evaluated a single oral dose given prior to scanning. While this approach establishes a baseline of resting state blood flow that changes with different task-related paradigms or differs from placebo or healthy controls in response to a preexisting condition, they do not address the effects of repeated exposure or the potential for dose-dependent changes in activity, consistent with drug target specificity.

Pharmacological MRI (phMRI) is a non-invasive method to evaluate neural circuitry involved in the behavioral effects of drugs independent of their specific biochemical mechanism [20]. To our knowledge, no published reports, in either animals or humans, have used phMRI to assess the immediate dose-dependent effects of CBD on global brain activity. Therefore, the goal of the present study was to characterize the dose-dependent changes in brain activity induced by CBD. Given that CBD may have a narrow dose range, impact multiple targets, and show context-dependent efficacy, phMRI is an ideal method to globally assess the integrated effects of CBD across multiple neural circuits to understand how CDB may impact anxiety and fear. We predict that at a certain dose there would be a decrease in relative activity, assessed using BOLD, in neural circuitry controlling stress-related behaviors. To test our prediction, we imaged awake mice using three different doses of CBD.

\section{Methods}

\section{Animal usage}

Male C57BL/J6 mice $(n=60)$, ages $100-120$ days, weighing between $28-30 \mathrm{~g}$, were obtained from Charles River Laboratories (Wilmington, Massachusetts, USA). While a majority of phMRI studies have been conducted in rats [21], we chose to study mice based on previous work from our group on CBD induced changes in $N$-acyl-phosphatidylethanolamines-specific phospholipase D (NAPE-PLD) activity [22]. Mice were maintained on a 12:12 h lightdark cycle with lights on at 07:00 $\mathrm{h}$ and allowed access to food and water ad libitum. All mice were acquired and cared for in accordance with the guidelines published in the Guide for the Care and Use of Laboratory Animals (National Institutes of Health Publications No. 85-23, Revised 1985) and adhered to the National Institutes of Health and the American Association for Laboratory Animal Science guidelines. The protocols used in this study complied with the regulations of the Institutional
Animal Care and Use Committee at the Northeastern University and adhered to the ARRIVE guidelines for reporting in vivo experiments in animal research [23].

\section{Drug preparation and administration}

CBD was a gift from the Center for Drug Discovery (Northeastern University, Boston MA) and dissolved in $\mathrm{EtOH} /$ cremophor/saline 1:1:18 for I.P. injections. Following acclimation, mice were randomly assigned to one of four groups corresponding to EtOH/cremophor/saline vehicle, 3, 10, or $30 \mathrm{mg} / \mathrm{kg}$ I.P. CBD. The amount of drug was adjusted to deliver vehicle and each dose in a volume of $0.2 \mathrm{ml}$. To deliver drug remotely during the imaging session, a poly-ethylene tube (PE-20), approximately $30 \mathrm{~cm}$ in length, was positioned in the peritoneal cavity. The range of doses of CBD evaluated were taken from the literature [24-26].

\section{Awake mouse imaging Imaging system}

We used previously described awake mouse imaging techniques [27]. Briefly, we used a quadrature transmit/ receive volume coil customized for optimal space filling, anatomical resolution, and signal-to-noise. The mouse holder (Ekam Imaging; Boston, MA) fully stabilizes the head in a cushioned helmet, minimizing discomfort caused by ear bars and other restraint systems that are commonly used to immobilize the head for awake animal imaging. A movie showing the set-up of a mouse for awake imaging is available at http://www.youtube.com/ watch? $v=$ W5Jup13isqw. The effectiveness of this passive restraining system can be judged by the minimal level of motion artifact recorded during the imaging session as shown in Additional file 1: Figure S1. The average displacement in any orthogonal direction over the entire 15 min scanning session did not exceed $56 \mu \mathrm{m}$.

\section{Acclimation}

A week before imaging, mice were acclimated to the head restraint and the noise of the scanner [27]. The acclimation protocol was repeated over four consecutive days reducing autonomic nervous system-induced effects during awake animal imaging (e.g., changes in heart rate, respiration, corticosteroid levels and motor movements), to improve contrast-to-noise ratios and image quality [28]. Only mice that habituate to restraint were used in the analysis. Additionally, three mice died and five were lost to motion artifact or technical complications resulting in group sizes of $\mathrm{EtOH} /$ cremophor/saline vehicle $(\mathrm{n}=8)$, $3 \mathrm{mg} / \mathrm{kg}(\mathrm{n}=6), 10 \mathrm{mg} / \mathrm{kg}(\mathrm{n}=5)$, and $30 \mathrm{mg} / \mathrm{kg}(\mathrm{n}=7)$. 


\section{BOLD phMRI and pulse sequence}

Experiments were conducted using a Bruker Biospec 7.0T/20-cm USR horizontal magnet (Bruker; Billerica, MA) and a 20-G/cm magnetic field gradient insert $(\mathrm{ID}=12 \mathrm{~cm})$ capable of a $120-\mu \mathrm{sec}$ rise time. At the beginning of each imaging session, a high-resolution anatomical data set was collected using the rapid acquisition relaxation enhanced (RARE) pulse sequence (18 slices; $0.75 \mathrm{~mm}$; field of view (FOV) $1.8 \mathrm{~cm}$; data matrix $128 \times 128$; time to repeat (TR) $2.1 \mathrm{~s}$; time to echo (TE) $12.4 \mathrm{~ms}$; Effective TE $48 \mathrm{~ms}$; number of averages (NEX) 6; $6.5 \mathrm{~min}$ acquisition time). Functional images were acquired using a multi-slice $\underline{H}$ alf Fourier $\underline{\text { Acquisition }} \underline{\mathrm{Sin}}$ gle Shot Turbo Spin Echo (HASTE) pulse sequence (18 slices; $0.75 \mathrm{~mm}$; FOV $1.8 \mathrm{~cm}$; data matrix $96 \times 96$; TR $6 \mathrm{~s}$; TE $4 \mathrm{~ms}$; Effect ET $24 \mathrm{~ms} ; 15 \mathrm{~min}$ acquisition time; in-plane resolution $187.5 \mu \mathrm{m}^{2}$ ). Spin echo is required to achieve the high anatomical fidelity required for data registration to the mouse MRI atlas as shown in Additional file 1: Figure S2 [29]. Each functional imaging session consisted of uninterrupted data whole brain scans, 150 scan repetitions, total elapsed time $15 \mathrm{~min}$. The control window included the first 50 scan repetitions, a $5 \mathrm{~min}$ baseline. Following the control window, an I.P. injection of drug was given followed by a 10 min stimulation window consisting of acquisitions 50-150.

The dose-dependent effect of CBD on brain activity was quantified by measuring positive and negative percent changes in BOLD signal relative to baseline as previously described [30]. A complete description of the data analysis is provided in Additional file 1: phMRI analysis.

\section{Resting state functional connectivity}

Sixty min prior to imaging mice were injected I.P. with $\mathrm{EtOH} /$ cremophor/saline vehicle $(\mathrm{n}=10)$ or $10 \mathrm{mg} / \mathrm{kg}$ $\operatorname{CBD}(n=10)$. The mice were then anesthetized and fitted into the coil as described above. Mice were maintained under light $1 \%$ isoflurane anesthesia (ambient air mix), adjusted to hold the respiratory rate between 50-60 breaths/min as compared to a normal rate of $85-90$ breaths $/ \mathrm{min}$. Scans were collected using a spin-echo triple-shot EPI sequence (imaging parameters: matrix size $=96 \times 96 \times 20(\mathrm{H} \times \mathrm{W} \times \mathrm{D}), \mathrm{TR} / \mathrm{TE}=1000 / 15 \mathrm{~ms}$, voxel size $=0.312 \times 0.312$, slice thickness $=1.2 \mathrm{~mm}$, with 200 repetitions, total time $10 \mathrm{~min}$. The data processing, normalization and group level analysis is described in detail in Additional file 1.

\section{Resting state BOLD functional connectivity analysis Degree centrality}

All network analysis was computed with Gephi, an opensource network analysis and visualization software [31].
Absolute values of the $\mathrm{CBD}$ and vehicle symmetric connectivity matrices were imported, and edges were loaded as undirected networks. A complete description of the graph theory analysis is provided in Additional file 1: Graph Theory Analysis.

\section{CBD analysis}

To validate that there was a dose-dependent change in CBD levels, serum levels of cannabinoids were analyzed [22]. In brief, methanolic extracts of $90 \mu \mathrm{l}$ of serum were partially purified on $\mathrm{C} 18$ solid phase extraction columns (Zorbax) and eluants were analyzed using HPLC/MS/ MS (API 3000, Applied Biosystems). Deuterium-labeled anandamide elutes in the same fraction as CBD and was used as an internal standard to monitor recovery. Levels of CBD and THC were analyzed using standard curves with Analyst Software as previously described [22]. During analysis it was discovered that each of the samples contained a small fraction THC in addition to CBD. This can occur during synthesis and is often unknown if the levels are not analyzed. The plasma ratio in each dose was ca 25:1 CBD:THC (Additional file 1: Figure S3B).

\section{Results}

Shown in Table 1 is a truncated list of 35 out of 138 brain areas ranked in order of their significance for change in positive BOLD volume of activation (number of voxels). Reported is the median number of voxels significantly activated $10 \mathrm{~min}$ post injection of vehicle (Veh), 3, 10 and $30 \mathrm{mg} / \mathrm{kg}$ of CBD with a critical value $\alpha<0.05$. Shown are $\mathrm{p}$ values and effect size (omega square $\omega^{2}$ ) calculations for each brain area. Additional file 1: Table S1 for positive BOLD volume of activation is provided for all 138 brain areas. Areas highlighted in gold show an inverted $\mathrm{U}$-shape dose response as commonly reported in the literature with the $10 \mathrm{mg} / \mathrm{kg}$ dose which produced a mean plasma concentration of $115 \mathrm{mg} / \mathrm{ml}$ (Additional file 1: Figure S3) being most effective [24-26]. Note that these areas are associated with the olfactory bulb (e.g., glomerular layer, granular layer) and prefrontal cortex (e.g., frontal association, orbital, infralimbic and prelimbic cortices) as shown in Fig. 1. In contrast, many of the areas highlighted in green show a U-shaped dose response (e.g., flocculus cerebellum, crus ansiform lobule, pontine area with the $3 \mathrm{mg}$ dose being most effective and the $10 \mathrm{mg}$ least effective. There are no brain areas that show a stepwise dose-dependent increase in brain activity. The areas highlighted in green are all located in hindbrain, brainstem, and cerebellum (see Fig. 1). The areas highlighted in blue, all of which have some of the lowest effect sizes, show both U- and inverted U-shaped responses and are located between the forebrain and hindbrain areas. 
Table 1 Positive bold volume of activation

\begin{tabular}{|c|c|c|c|c|c|c|}
\hline Brain area & Veh & $3 \mathrm{mg}$ & $10 \mathrm{mg}$ & $30 \mathrm{mg}$ & P val & $\omega^{2}$ \\
\hline Glomerular layer & 3 & 9 & 76 & 34 & 0.001 & 0.806 \\
\hline Granular cell layer & 2 & 8 & 89 & 23 & 0.001 & 0.757 \\
\hline Anterior olfactory area & 7 & 19 & 64 & 33 & 0.001 & 0.701 \\
\hline Flocculus cerebellum & 29 & 41 & 10 & 19 & 0.001 & 0.635 \\
\hline Medullary reticular ventral area & 0 & 27 & 5 & 0 & 0.001 & 0.578 \\
\hline Reticulotegmental nucleus & 25 & 0 & 0 & 0 & 0.002 & 0.546 \\
\hline Locus coeruleus & 0 & 25 & 0 & 0 & 0.002 & 0.537 \\
\hline Frontal association ctx & 3 & 12 & 85 & 26 & 0.003 & 0.482 \\
\hline Crus of ansiform lobule & 21 & 40 & 3 & 14 & 0.005 & 0.448 \\
\hline Lateral lemniscus & 42 & 33 & 8 & 4 & 0.006 & 0.428 \\
\hline Orbital ctx & 3 & 8 & 60 & 8 & 0.007 & 0.411 \\
\hline Pontine area & 29 & 15 & 3 & 27 & 0.007 & 0.401 \\
\hline Spinal trigeminal nuclear area & 22 & 33 & 9 & 38 & 0.007 & 0.4 \\
\hline Infralimbic ctx & 0 & 0 & 73 & 56 & 0.008 & 0.386 \\
\hline Prelimbic ctx & 0 & 5 & 53 & 2 & 0.009 & 0.384 \\
\hline Cuneate area & 50 & 48 & 0 & 0 & 0.009 & 0.381 \\
\hline 5th cerebellar lobule & 0 & 7 & 0 & 0 & 0.01 & 0.368 \\
\hline Paramedian lobule & 10 & 33 & 0 & 8 & 0.01 & 0.368 \\
\hline 6th cerebellar lobule & 17 & 38 & 0 & 3 & 0.011 & 0.364 \\
\hline Pontine reticular nucleus caudal & 26 & 13 & 0 & 0 & 0.011 & 0.361 \\
\hline Solitary tract area & 5 & 37 & 0 & 21 & 0.016 & 0.322 \\
\hline Parvicellular reticular area & 31 & 30 & 4 & 27 & 0.017 & 0.318 \\
\hline Vestibular area & 3 & 42 & 0 & 11 & 0.017 & 0.318 \\
\hline Simple lobule cerebellum & 12 & 26 & 0 & 0 & 0.021 & 0.299 \\
\hline 4th cerebellar lobule & 12 & 10 & 0 & 0 & 0.022 & 0.294 \\
\hline Principal sensory $n$. trigeminal & 25 & 28 & 8 & 10 & 0.023 & 0.291 \\
\hline Lemniscal area & 15 & 16 & 0 & 0 & 0.024 & 0.286 \\
\hline Entorhinal ctx & 30 & 40 & 18 & 16 & 0.028 & 0.27 \\
\hline Prepositus area & 0 & 9 & 0 & 14 & 0.031 & 0.26 \\
\hline 3rd cerebellar lobule & 7 & 9 & 0 & 0 & 0.038 & 0.239 \\
\hline Primary motor ctx & 10 & 14 & 50 & 19 & 0.04 & 0.235 \\
\hline Inferior colliculus & 20 & 39 & 3 & 5 & 0.04 & 0.233 \\
\hline 10th cerebellar lobule & 0 & 0 & 0 & 3 & 0.042 & 0.23 \\
\hline Periaqueductal gray & 19 & 11 & 1 & 12 & 0.046 & 0.22 \\
\hline Caudate putamen & 6 & 10 & 48 & 27 & 0.049 & 0.214 \\
\hline
\end{tabular}

This table is a truncated list of 35 out of 138 brain areas ranked in order of their significance for change in positive BOLD volume of activation (number of voxels). Reported is the median number of voxels significantly activated 10 min post injection of vehicle (0), 3, 10 and $30 \mathrm{mg} / \mathrm{kg}$ I.P. doses of CBD. Show are p values and effect size (omega square $\omega^{2}$ ) for each brain area. The significance levels for FDR was $p \leq 0.051$. Areas highlighted in gold are associated with the olfactory system and prefrontal cortex. Areas highlighted in green are in the hindbrain brainstem and cerebellum. The areas highlighted in blue are located between the forebrain and hindbrain areas

Shown in Table 2 is a truncated list of 50 out of 138 brain areas ranked in order of their significance for change in negative BOLD volume of activation. A false discovery rate for multi-comparisons gives a significance level of $\mathrm{p} \leq 0.073$. The areas highlighted in gold are again the olfactory bulb and prefrontal cortex, as in Table 1, 
but the pattern is reversed, with areas like the glomerular layer and orbital cortex showing a U-shaped dose response. The $3 \mathrm{mg} / \mathrm{kg}$ dose is most effective in causing a negative change in BOLD signal while the $10 \mathrm{mg} / \mathrm{kg}$ dose is least effective. This reversed pattern between positive and negative BOLD is also true for the areas highlighted in green representing the hindbrain, brainstem, and cerebellum. The $10 \mathrm{mg} / \mathrm{kg}$ dose is most effective in causing a negative change in BOLD signal with many areas presenting with the inverted U-shaped dose response. The brain areas highlighted in blue are located along the rostral/caudal axis between the forebrain and hindbrain (Fig. 1).

The data from Tables $1 \& 2$ are shown in the respective bar graphs in Fig. 1. In forebrain, the average of all medians scores from areas in gold for positive BOLD volume of activation, was higher in the $10 \mathrm{mg} / \mathrm{kg}$ group compared to either vehicle $(\mathrm{p}<0.0001)$ or the $3 \mathrm{mg} / \mathrm{kg}$ $(p=0.0133)$ (Fig. 1a). There were no significant differences between doses for the midbrain areas. In the hindbrain, the average of all median scores from areas in blue for positive BOLD, volume of activation for CBD (10 mg/ $\mathrm{kg}$ ) was lower than that observed following vehicle $(\mathrm{p}=0.0012)$. The median number of voxels for $3 \mathrm{mg} / \mathrm{kg}$ was greater than both $10 \mathrm{mg} / \mathrm{kg}(\mathrm{p}<0.00001)$ and $30 \mathrm{mg} /$ $\mathrm{kg}(\mathrm{p}=0.0019)$. There was no difference in voxel activation in the hindbrain between vehicle and $3 \mathrm{mg} / \mathrm{kg}$. There is a baseline of voxel activation in the brainstem/cerebellar areas in awake mouse imaging that is reduced by 10 and $30 \mathrm{mg} / \mathrm{kg}$ doses.

This relationship between $\mathrm{CBD}$ doses and positive BOLD was reversed for negative BOLD (Fig. 1b). Unlike positive BOLD areas highlighted in gold, olfactory bulb, and prefrontal cortex, show a U-shaped dose response. The $3 \mathrm{mg} / \mathrm{kg}$ the most effective in causing a negative change in BOLD signal while $10 \mathrm{mg} / \mathrm{kg}$ was least effective. This reversed pattern between positive and negative BOLD is also true with the hindbrain brainstem, and cerebellum showing an inverted U-shape, with $10 \mathrm{mg} /$ $\mathrm{kg}$ dose stimulating the strongest negative BOLD signal (Fig. 1b). In the forebrain, there is a baseline of negative BOLD voxels (median ca 40 ) that is significantly reduced with either $10 \mathrm{mg} / \mathrm{kg}(\mathrm{p}=0.0197)$ or $3 \mathrm{mg} / \mathrm{kg} C B D$ $(p=0.0043)$ versus vehicle. In the hindbrain, the baseline of negative BOLD voxels (median ca 16) was increased with both $10 \mathrm{mg} / \mathrm{kg}$ and $3 \mathrm{mg} / \mathrm{kg}$ CBD ( $\mathrm{p} \leq 0.0001$ for each comparison) over vehicle. In the midbrain brain areas, $3 \mathrm{mg} / \mathrm{kg}$ increased the median number of negative voxels over vehicle $(p=0.0389)$, whereas $30 \mathrm{mg} / \mathrm{kg}$ was associated with a lower number of negative voxels than the $3 \mathrm{mg} / \mathrm{kg}(\mathrm{p}=0.0006)$.

Figure 2 summarizes the effect of the $10 \mathrm{mg} / \mathrm{kg}$ of CBD on BOLD signal, with tables showing significant changes, negative and positive, BOLD activation. The 3D image summarizes the location of the brain areas presenting with positive (red) and negative (blue) activation. The distribution is polarized along the rostral-caudal axis with positive BOLD localized to the forebrain and negative signal changes confined to the hindbrain. The forebrain areas are represented by the olfactory system (e.g., granular and glomerular layers of olfactory bulb, anterior olfactory area, and tenia tecta) and the prefrontal cortex (e.g., prelimbic, frontal association, orbital, infralimbic, 2nd and primary cortices). Connecting these bilateral forebrain areas is the forceps minor of the corpus callosum. The negative BOLD in the hindbrain is represented by the cerebellum (e.g., 2nd-6th lobules, simple lobule, crus of ansiform lobule flocculus) and ascending reticular activating system (ARAS) (e.g., dorsal raphe, parabrachial nucleus (n.), parvicellular reticular n., gigantocellularis, pedunculopontine $n$., pontine reticular $n$. mesencephalic reticular n.). In addition to volume of activation i.e. number of voxels activated with CBD treatment, changes in positive and negative BOLD signal over time, another measure of functional activity, are presented for the ARAS and forebrain. Each time point or image acquisition is the average BOLD signal of all brain areas comprising the ARAS and all areas in the forebrain. CBD has no significant effect on positive BOLD signal in the ARAS; instead, vehicle causes a greater, albeit small and at the level of threshold (above noise) increase in CBD (2-way ANOVA, $\mathrm{F}_{(1,88)}=8.48, \mathrm{p}=0.0045 ; \mathrm{CBD}<\mathrm{Veh}$ ). In the forebrain this pattern was reversed. CBD caused a significant increase in positive BOLD versus vehicle $\left(\mathrm{F}_{(1,167)}=6.025, \mathrm{p}=0.0199 ; \mathrm{CBD}>\mathrm{Veh}\right)$ while being significantly less than vehicle for negative BOLD $\left(\mathrm{F}_{(1,167)}=5.008, \mathrm{p}=0.026 \mathrm{CBD}<\mathrm{Veh}\right)$.

(See figure on next page.)

Fig. 1 Polarized Positive and Negative BOLD. The color-coded 3D reconstructions for positive and negative BOLD denote the location of the brain areas comprising the hindbrain, midbrain, and forebrain, respectively. The bar graphs below show the average median number of voxels from each of these brain regions for vehicle, 3,10 , and $30 \mathrm{mg} / \mathrm{kg}$ I.P. doses of CBD. For forebrain positive BOLD: $\left({ }^{* * *} \mathrm{p}<0.0001,10 \mathrm{mg}>\right.$ Veh); $\left({ }^{*} \mathrm{p}=0.0133\right.$, $10 \mathrm{mg}>3 \mathrm{mg})$. For hindbrain positive BOLD: $\left({ }^{* *} \mathrm{p}=0.0012,10 \mathrm{mg}<\mathrm{Veh}\right) ;\left({ }^{* * * *} \mathrm{p}<0.00001,10 \mathrm{mg}<3 \mathrm{mg}\right) ;\left({ }^{* *} \mathrm{p}=0.0019,10 \mathrm{mg}<3 \mathrm{mg}\right)$. For forebrain negative BOLD: $\left({ }^{*} p=0.0197,10 \mathrm{mg}<\right.$ Veh); $\left({ }^{* *} p=0.004310<3 \mathrm{mg}\right)$. For midbrain negative BOLD: $\left({ }^{*} p=0.0389 ; 3 \mathrm{mg}>\operatorname{Veh}\right) ;\left({ }^{* * *} p=0.0006\right.$,

$3 \mathrm{mg}>30 \mathrm{mg}$ ). For hindbrain negative BOLD:D voxels (median ca 16) that is significantly increased with the $10 \mathrm{mg}$ dose of CBD over vehicle and $3 \mathrm{mg}\left({ }^{* * *} \mathrm{p} \leq 0.0001,10 \mathrm{mg}>\right.$ Veh, $\left.10 \mathrm{mg}>3 \mathrm{mg}\right)$ 
a

\section{Postive BOLD}
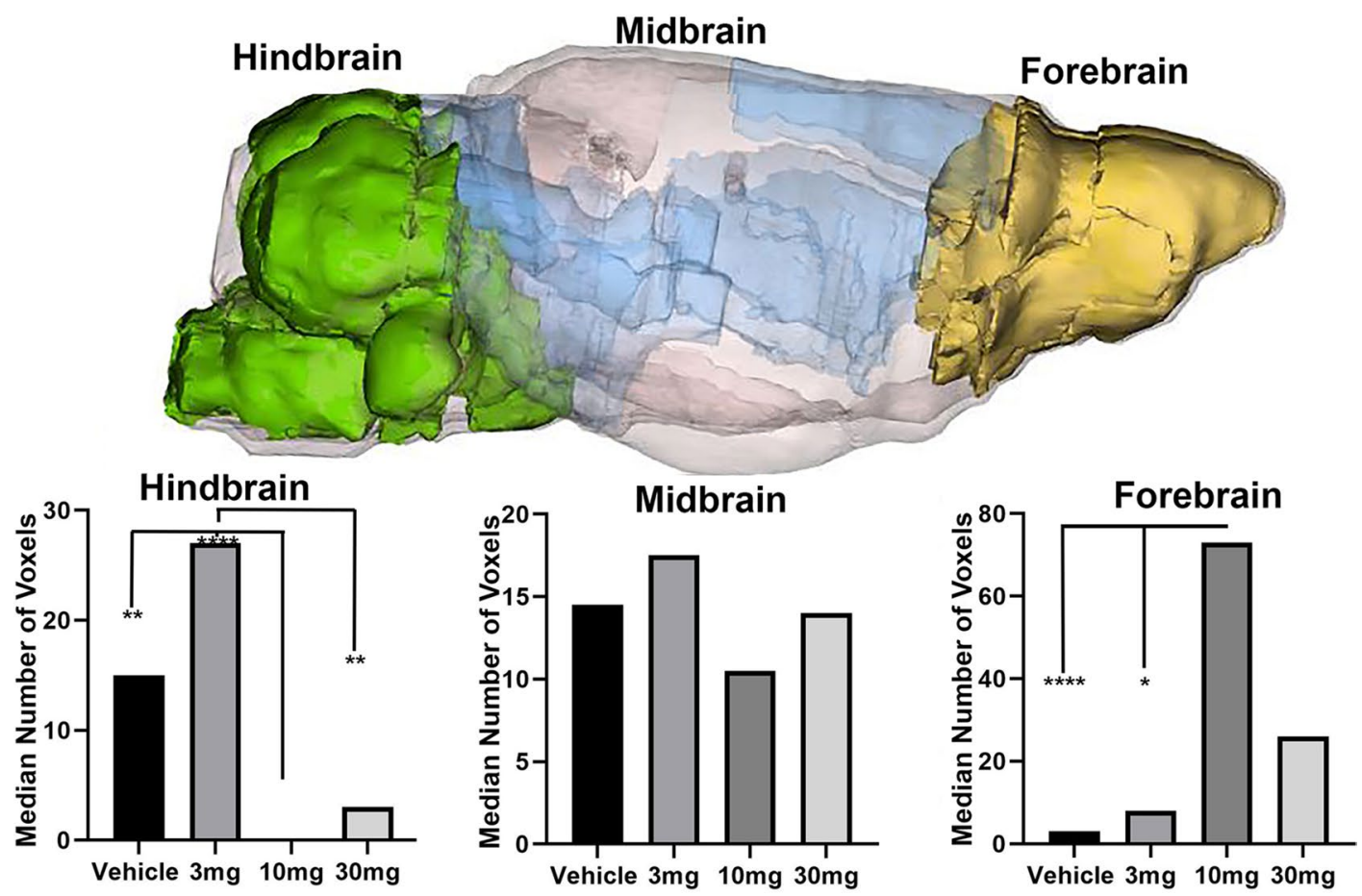

b

\section{Negative BOLD}
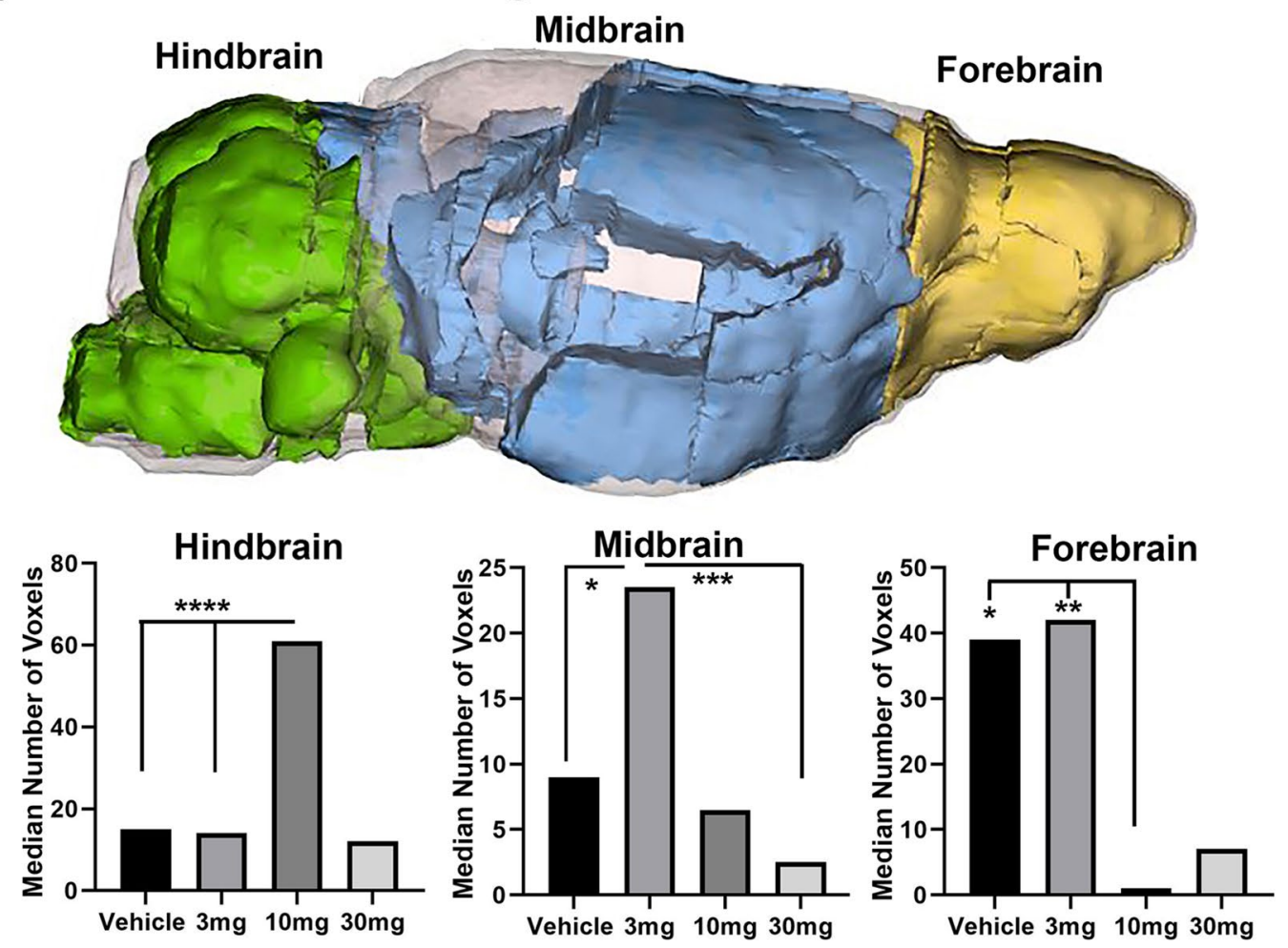
Table 2 Negative BOLD volume of activation

\begin{tabular}{|c|c|c|c|c|c|c|}
\hline \multicolumn{7}{|c|}{ Negative BOLD } \\
\hline Brain area & Veh & $3 \mathrm{mg}$ & $10 \mathrm{mg}$ & $30 \mathrm{mg}$ & P val & $\omega^{2}$ \\
\hline Anterior olfactory area & 44 & 46 & 4 & 0 & 0.001 & 0.691 \\
\hline Glomerular layer & 50 & 60 & 4 & 20 & 0.001 & 0.672 \\
\hline Granular cell layer & 39 & 61 & 0 & 7 & 0.001 & 0.653 \\
\hline Frontal association ctx & 64 & 39 & 2 & 2 & 0.001 & 0.555 \\
\hline Lateral geniculate & 0 & 22 & 9 & 0 & 0.002 & 0.448 \\
\hline 2nd cerebellar lobule & 3 & 16 & 51 & 45 & 0.002 & 0.464 \\
\hline Reticulotegmental nucleus & 3 & 17 & 66 & 0 & 0.003 & 0.519 \\
\hline Parvicellular reticular area & 19 & 11 & 67 & 32 & 0.003 & 0.477 \\
\hline Ventral medial hypothalamic area & 2 & 25 & 22 & 0 & 0.003 & 0.410 \\
\hline Parabrachial area & 0 & 10 & 58 & 0 & 0.003 & 0.440 \\
\hline Rostral piriform ctx & 24 & 27 & 6 & 7 & 0.004 & 0.387 \\
\hline Orbital ctx & 25 & 42 & 1 & 8 & 0.004 & 0.444 \\
\hline Medullary reticular ventral area & 30 & 7 & 58 & 0 & 0.005 & 0.456 \\
\hline Simple lobule cerebellum & 4 & 17 & 58 & 39 & 0.006 & 0.413 \\
\hline 3rd cerebellar lobule & 0 & 2 & 92 & 10 & 0.006 & 0.398 \\
\hline Median raphe area & 4 & 4 & 56 & 2 & 0.008 & 0.350 \\
\hline Accumbens shell & 11 & 17 & 0 & 2 & 0.009 & 0.330 \\
\hline Flocculus cerebellum & 15 & 24 & 32 & 6 & 0.010 & 0.409 \\
\hline 6th cerebellar lobule & 23 & 8 & 85 & 20 & 0.010 & 0.377 \\
\hline Intermediate reticular area & 26 & 28 & 80 & 46 & 0.011 & 0.336 \\
\hline Mesencephalic reticular formation & 1 & 14 & 24 & 3 & 0.011 & 0.312 \\
\hline 7 th cerebellar lobule & 62 & 22 & 89 & 0 & 0.012 & 0.308 \\
\hline Ventral pallidum & 8 & 21 & 0 & 0 & 0.013 & 0.283 \\
\hline Pontine reticular nucleus caudal & 3 & 12 & 61 & 12 & 0.014 & 0.342 \\
\hline Crus of ansiform lobule & 24 & 16 & 86 & 37 & 0.014 & 0.351 \\
\hline Spinal trigeminal nuclear area & 28 & 19 & 44 & 15 & 0.015 & 0.337 \\
\hline Gigantocell aris reticular area & 15 & 17 & 75 & 51 & 0.016 & 0.312 \\
\hline Caudal piriform ctx & 23 & 23 & 24 & 5 & 0.016 & 0.292 \\
\hline Dorsal raphe & 0 & 25 & 57 & 8 & 0.017 & 0.299 \\
\hline Cuneate area & 0 & 10 & 64 & 0 & 0.017 & 0.325 \\
\hline 4th cerebellar lobule & 0 & 1 & 46 & 15 & 0.018 & 0.311 \\
\hline Pontine area & 3 & 32 & 51 & 0 & 0.022 & 0.306 \\
\hline Paramedian lobule & 30 & 21 & 59 & 9 & 0.022 & 0.302 \\
\hline Pedunculopontine tegmental area & 5 & 10 & 74 & 8 & 0.023 & 0.276 \\
\hline Pontine reticular nucleus oral & 5 & 7 & 31 & 0 & 0.023 & 0.271 \\
\hline Primary motor ctx & 14 & 24 & 2 & 3 & 0.024 & 0.278 \\
\hline Vestibular area & 22 & 6 & 72 & 43 & 0.024 & 0.292 \\
\hline Medullary reticular dorsal area & 31 & 41 & 41 & 0 & 0.025 & 0.230 \\
\hline Olfactory tubercles & 25 & 27 & 7 & 2 & 0.026 & 0.236 \\
\hline Insular rostral ctx & 27 & 22 & 4 & 14 & 0.026 & 0.257 \\
\hline 5th cerebellar lobule & 25 & 2 & 92 & 87 & 0.028 & 0.301 \\
\hline Lateral posterior thalamic area & 0 & 26 & 3 & 0 & 0.029 & 0.205 \\
\hline Olivary complex & 4 & 28 & 56 & 8 & 0.031 & 0.245 \\
\hline Diagonal band of Broca & 13 & 36 & 0 & 0 & 0.033 & 0.192 \\
\hline Prepositus area & 34 & 3 & 100 & 64 & 0.034 & 0.276 \\
\hline Primary somatosensory ctx & 10 & 24 & 2 & 4 & 0.037 & 0.214 \\
\hline Subiculum & 3 & 15 & 28 & 11 & 0.041 & 0.226 \\
\hline Inferior colliculus & 0 & 5 & 39 & 25 & 0.042 & 0.228 \\
\hline periaqueductal gray & 0 & 28 & 31 & 13 & 0.047 & 0.216 \\
\hline Lemniscal area & 2 & 6 & 34 & 0 & 0.049 & 0.225 \\
\hline
\end{tabular}


Table 2 (continued)

This Table is a truncated list of 50 out of 138 brain areas ranked in order of their significance for change in negative BOLD volume of activation. Reported is the median number of voxels significantly activated $10 \mathrm{~min}$ post injection of vehicle (0), 3, 10 and $30 \mathrm{mg} / \mathrm{kg}$ I.P. doses of CBD. Show are p values and effect size (omega square $\omega^{2}$ ) for each brain area. The significance level for FDR was $p \leq 0.073$. The areas highlighted in gold are the olfactory bulb and prefrontal cortex. Areas highlighted in green are localized to the hindbrain brainstem, and cerebellum. The brain areas highlighted in blue are located along the rostral/caudal axis between the forebrain and hindbrain

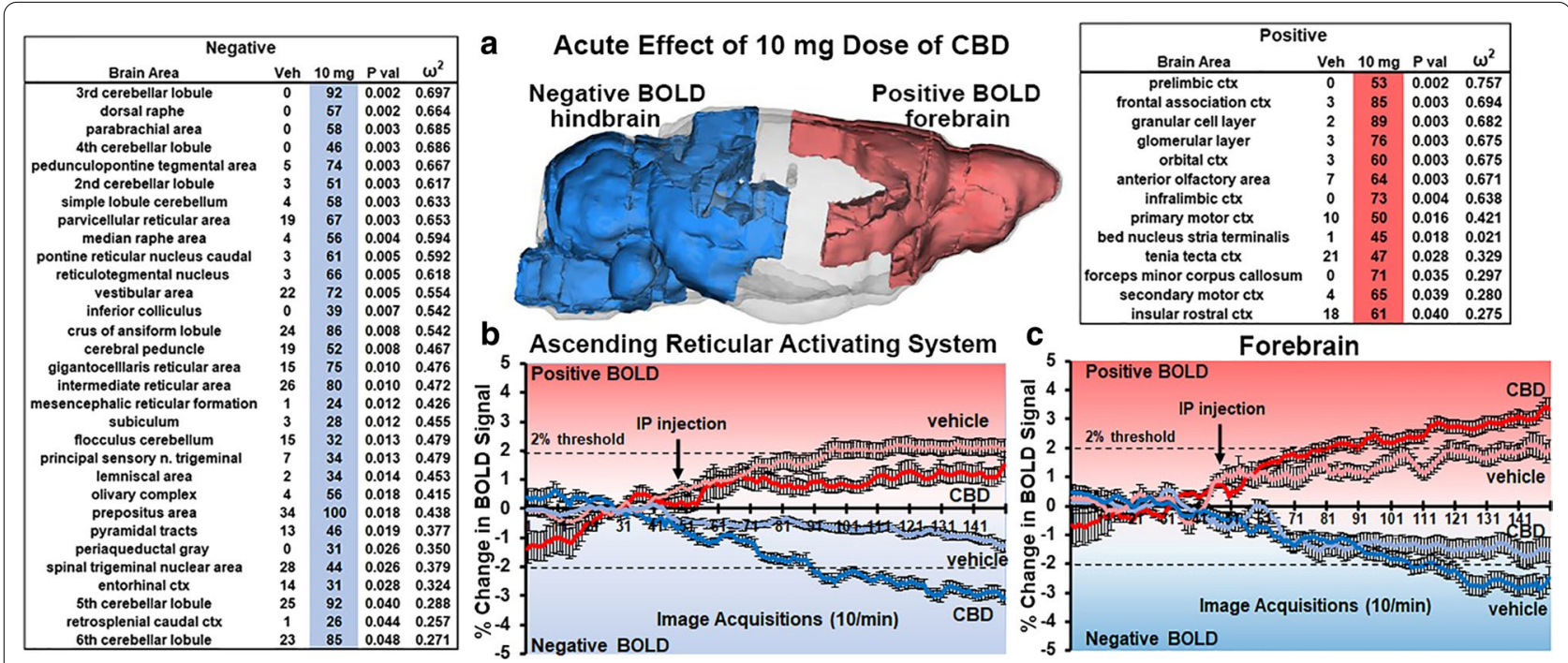

Fig. 2 Acute Effects of $10 \mathrm{mg}$ Dose of CBD. The tables show a truncated list of 31 and 13 out of 138 brain areas ranked in order of their significance for changes in negative and positive BOLD volume of activation, respectively in response to the $10 \mathrm{mg} / \mathrm{kg}$ I.P. dose of CBD. The 3D image (a) summarizes the location of these brain areas presenting with positive (red) and negative (blue) BOLD volume of activation. Below are graphs of BOLD signal change over the 15 min imaging session for the ascending reticular activating system (ARAS) (b) and forebrain (c). Comparisons are made between vehicle and the $10 \mathrm{mg}$ dose of CBD. Shades of red denote positive changes and shades of blue negative changes. For ARAS positive BOLD: $(p=0.0045 ; C B D<$ Veh). For ARAS negative BOLD: $(p<0.0001 ; C B D>V e h)$. For forebrain positive BOLD $(p=0.0199 ; C B D>$ Veh). For forebrain negative BOLD: $(p=0.026 C B D>$ Veh $)$

Looking at changes in connectivity (degrees) between CBD and controls in major brain areas reveals a pattern of functional coupling consistent with the pronounced negative BOLD observed with phMRI (Fig. 3). Mice treated with $10 \mathrm{mg} / \mathrm{kg}$ CBD prior to imaging showed a significant decrease in coupling in all the hindbrain regions, midbrain, hypothalamus, and cortex. While there were no significant differences seen in forebrain regions of olfactory system, prefrontal cortex, the thalamus, or the amygdala. Interestingly, when the ARAS is combined as a node, the same pattern of uncoupling appears between the ARAS and all these major brain regions, except for the olfactory system, prefrontal cortex, thalamus, and amygdala (Additional file 1: Figure S4). The ARAS as a node, under the influence of CBD, may not be significantly less than these brain regions but it is positively correlated with specific brain areas within these areas (Fig. 4). The 2D maps show the neuroanatomical position of brain areas with increased coupling to the ARAS (highlighted in red) following CBD treatment compared to vehicle. The areas shown in gray comprise the ARAS. A 3D reconstruction of these areas is shown to the left. The olfactory system is a large part of the hyperconnectivity between the ARAS and these limbic forebrain regions. The wire diagram below shows the significant negative (blue) and positive (red) connections between the ARAS and specific areas in the primary olfactory system.

Shown in Fig. 5 are autoradiograms of in situ hybridization of NAPE-PLD from the Allen Brain Atlas [32].

(See figure on next page.)

Fig. 3 Regional Changes in Connectivity. Shown are 3D color coded images summarizing CBD-induced changes in connectivity (a) and box and whiskers plots (b) depicting differences in degree centrality in various subregions between vehicle and rats treated with $10 \mathrm{mg} / \mathrm{kg}$ CBD $60 \mathrm{~min}$ prior to imaging. The CBD group had significantly lower degree centrality of nodes within the hippocampus, hypothalamus, cortex, cerebellum, brainstem, basal ganglia, midbrain, and pons $\left({ }^{* *} \mathrm{p}<0.05\right.$, not significant $\left.=n s\right)$. There were no significant differences in degree within nodes of the amygdala, olfactory system, prefrontal cortex, or thalamus 


\section{CBD Treatment Decreases Functional Connectivity Across Multiple Brain Regions}

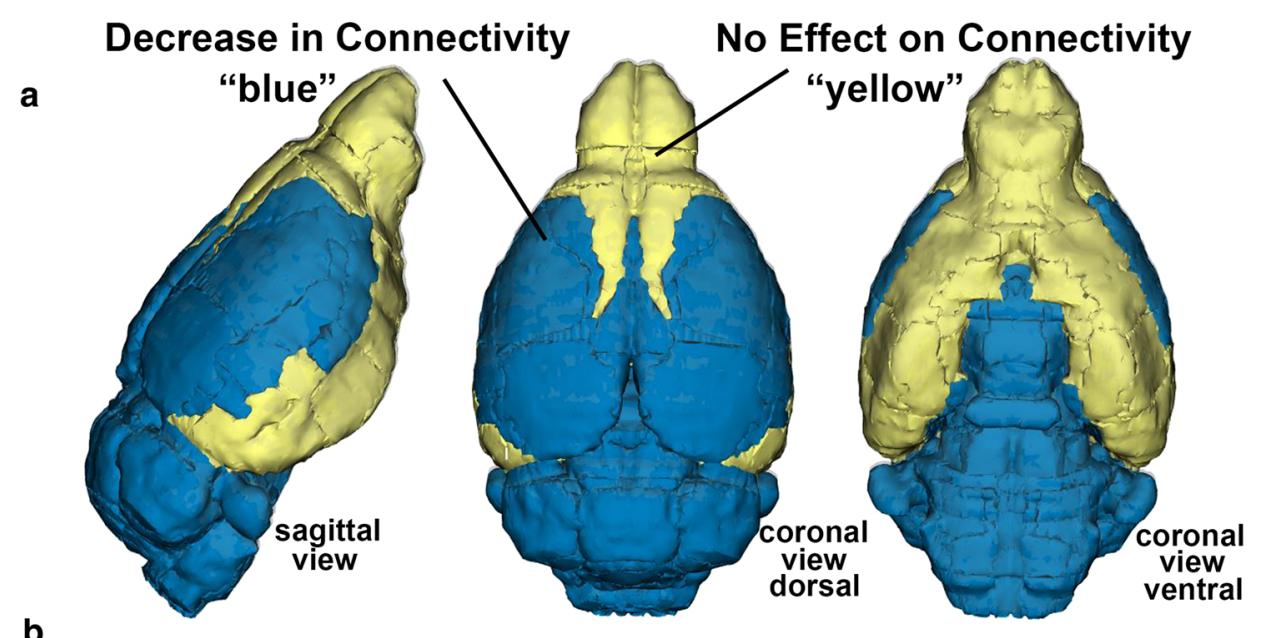

b
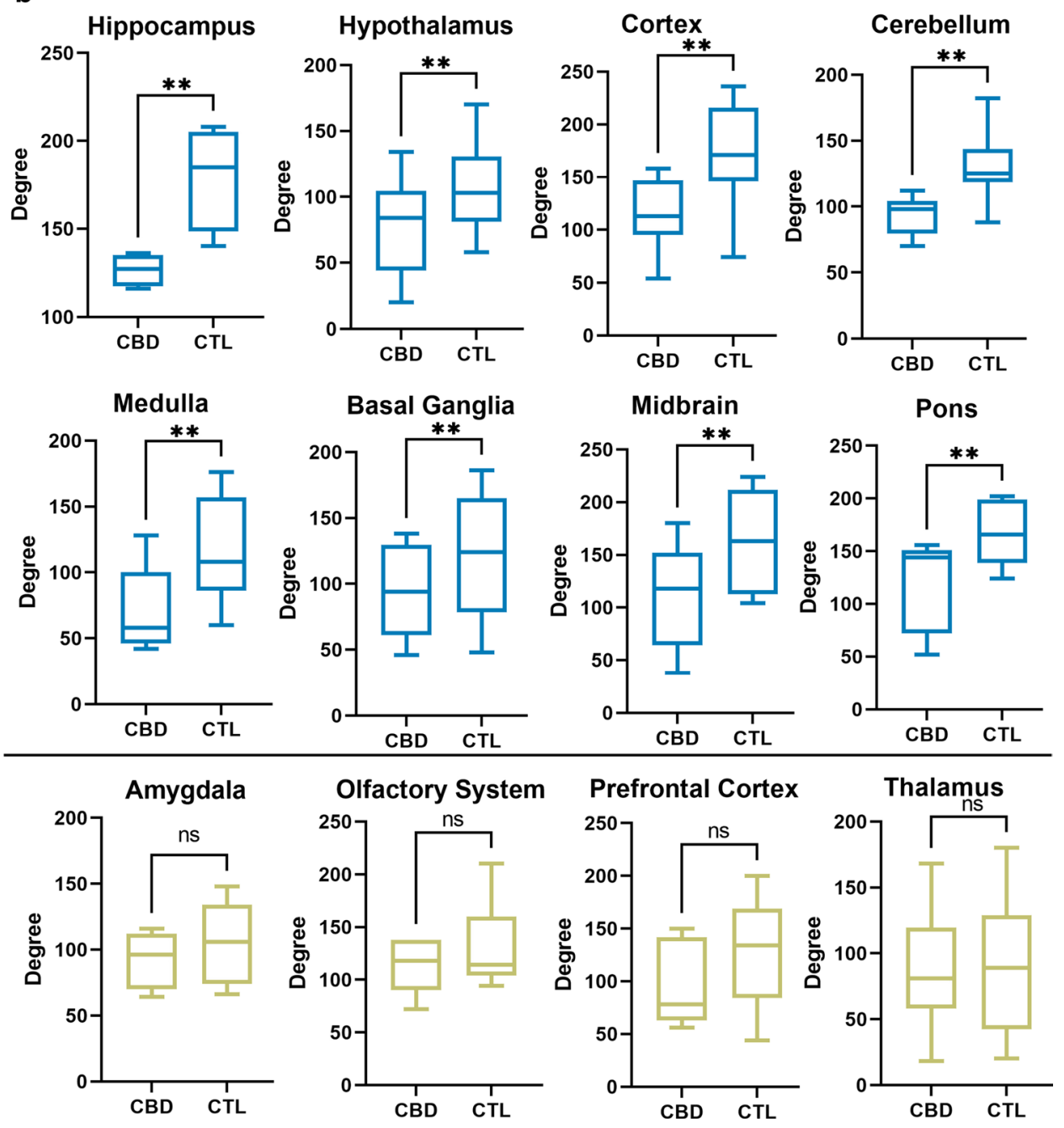


\section{Brains Areas with Enhanced Functional Connectivity to the ARAS \\ a following CBD Treatment}
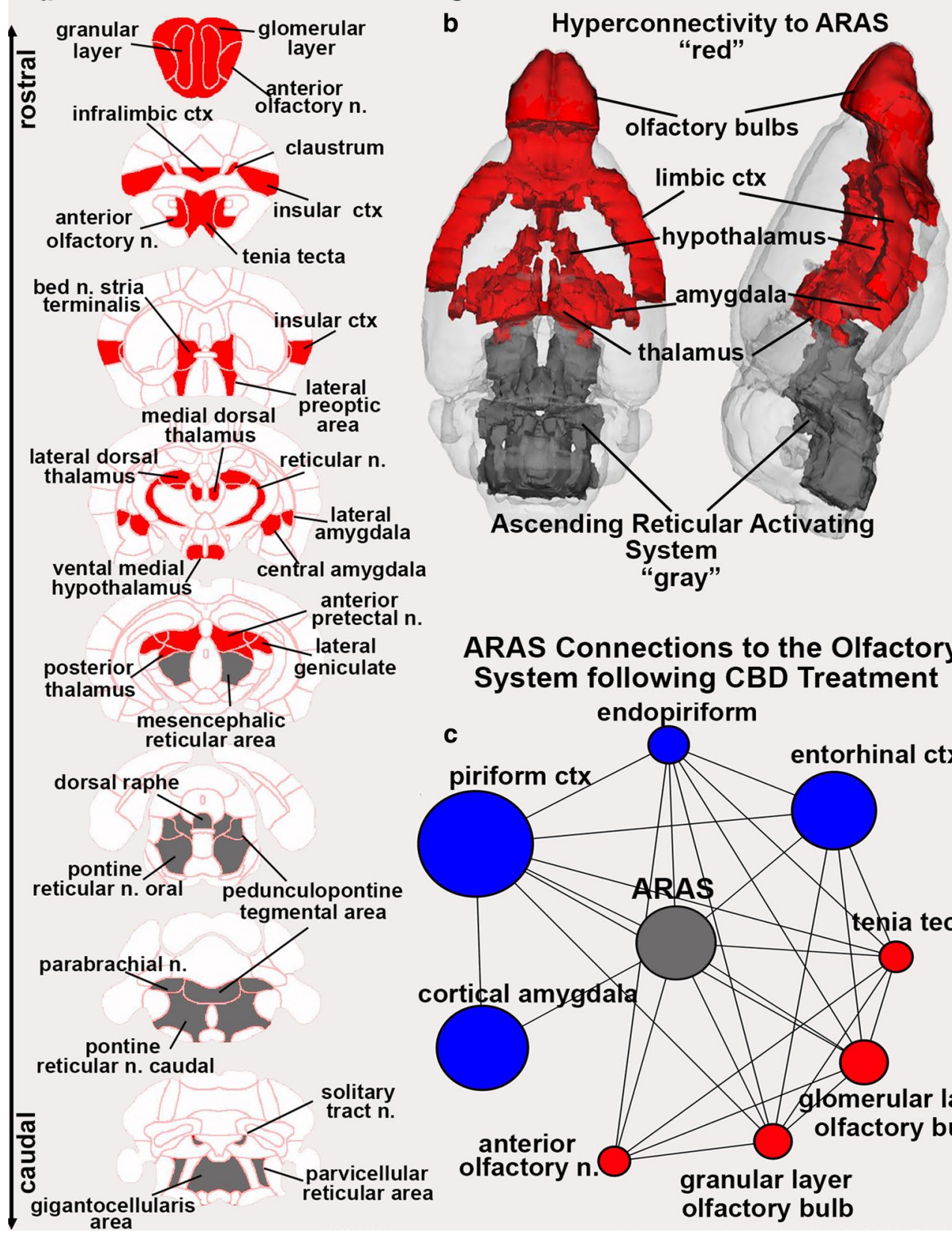

\section{ARAS Connections to the Olfactory System following CBD Treatment} endopiriform

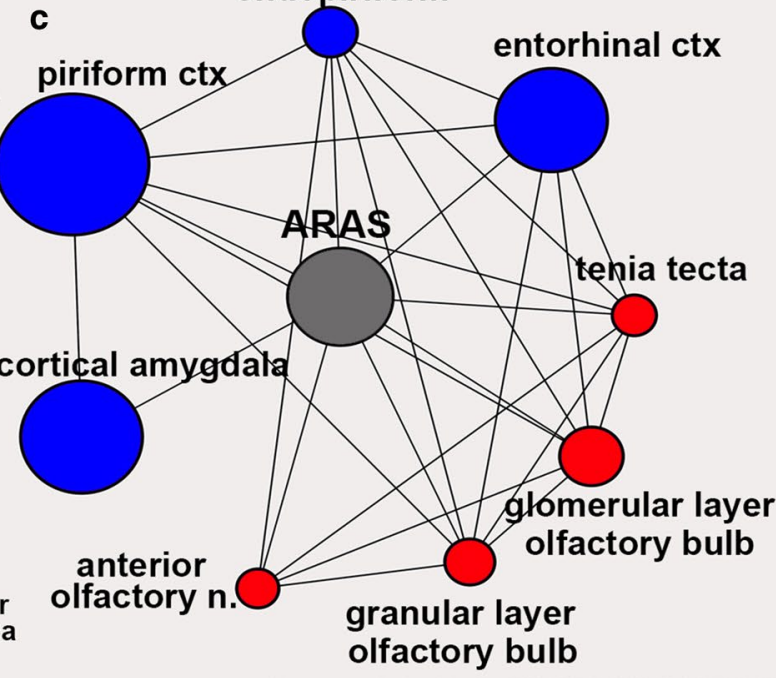

Fig. 4 Hyperconnectivity to the ARAS with CBD Treatment. Shown to the left (a) are 2D axial maps showing the location of brain areas (red) with enhanced coupling to the ARAS following CBD treatment. Areas in gray denote the location of brain areas comprising the ARAS. The 2D images are summarized in the 3D reconstruction of the red and gray brain areas $(\mathbf{b})$. The circle of connections beneath (c), display the neighboring nodes of the ARAS in the CBD treated group within the olfactory system. Nodes that have a greater degree centrality in the CBD group have been colored red, while nodes that have a greater degree centrality in the vehicle group have been colored blue. Node size has been scaled to reflect the relative difference in degree centrality between the vehicle and CBD group, with the larger nodes reflecting a larger difference in degree centrality

These are sagittal sections that extend from the midline laterally from top (A.) to bottom (B.). The signal intensity reflects the level of mRNA in specific brain areas. Note, in general, the forebrain olfactory system and hindbrain cerebellum have a high density of NAPE-PLD mRNA. All the areas comprising the ARAS 


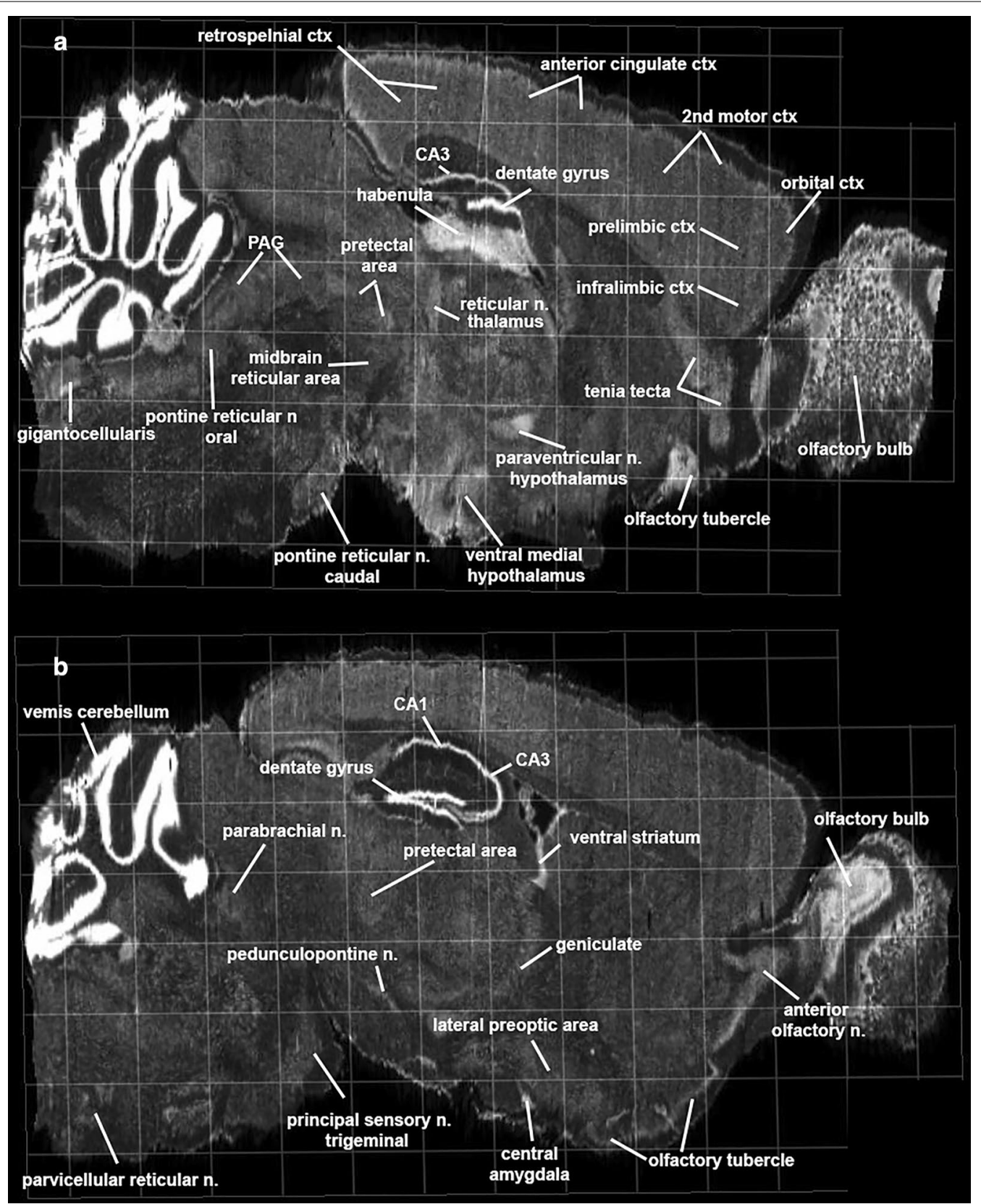

Fig. $5 \mathrm{~N}$-acyl-phosphatidylethanolamines -specific phospholipase D mRNA. Shown are autoradiograms of in situ hybridization of NAPD-PLD messenger RNA in mouse brain. The sagittal section A and B extend medial to lateral. Abbreviations PAG — periaqueductal gray. Image credit: Allen Institute

have NAPE-PLD mRNA (A. gigantocellularis, pontine reticular $\mathrm{n}$, oral, midbrain reticular $\mathrm{n}$., pontine reticular n. caudal; B. parabrachial n., pedunculopontine n., parvicellular reticular n.). Many of the areas shown in the $2 \mathrm{D}$ maps of positive ARAS connectivity to thalamus, amygdala, prefrontal, and olfactory system show high levels of NAPE-PLD mRNA (e.g., olfactory bulb, anterior olfactory n., tenia tecta, infralimbic ctx, lateral preoptic area, ventral medial hypothalamus, central amygdala, geniculate, reticular n. pretectal n.). 


\section{Discussion}

CBD produced activation in the prefrontal cortex and deactivation in the brainstem/cerebellum, particularly within the ascending reticular activating system (ARAS), with no changes apparent in the hypothalamus, amygdala, basal ganglia, or hippocampus. rsFC showed a decoupling of the hindbrain and midbrain regions, particularly the ARAS following CBD treatment. The integrated activity of the ARAS affects all aspects of cognitive and emotional behavior [33]. Interestingly, there were several areas of the brain that were positively coupled with the ARAS following CBD treatment. These area colocalize with a high density of $N$-acyl-phosphatidylethanolamines (NAPE) by a NAPE-specific phospholipase D (NAPE-PLD) mRNA [32]. NAPE-PLD is a constitutively active enzyme involved in the biosynthesis of $\mathrm{N}$-acylethanolamines, signaling lipids molecules like anandamide [34]. The rsFC showed hyperconnectivity and hypoconnectivity that was consistent with the phMRI data. These findings are discussed with respect to the many studies showing CBD can affect the emotional and cognitive behavior associated with anxious and fearful events and NAPE-PLD as a putative mechanism of action.

\section{Human imaging and CBD}

Several studies have used imaging to characterize the acute effect of CBD on brain activity in humans. SPECT imaging in volunteers diagnosed with anxiety disorder shows CBD increases blood flow in the cingulate cortex and reduces flow in the hippocampus while decreasing anxiety [35]. BOLD imaging in healthy volunteers, shows CBD decreases activation in the cerebellum, anterior cingulate, and amygdala, in a visual fear paradigm but not to neutral stimuli [15]. In healthy volunteers, CBD enhances caudate and hippocampal activation and fronto-striatal connectivity during salience processing [12, 13] and under resting state conditions [16], enhances auditory and visual processing [19] and effects working and episodic memory associated with an increase in blood flow to the hippocampus [14]. CBD alters functional coupling in cerebellum, frontal, and occipital cortices in patients with treatment resistant epilepsy [17] and attenuates hippocampal-striatal functional connectivity in psychosis patients [18]. All these studies gave oral doses of CBD prior to scanning, thus establishing a baseline of resting state blood flow that changed with different task-related paradigms or differed from placebo or healthy controls in response to a preexisting condition.

\section{Polarized positive and negative BOLD}

The data reported here in awake mice are not easily compared to the human imaging studies. As the only study of its kind, we are looking at the immediate, dose-dependent effects of CBD, administered I.P., on brain activity across 138 different brain areas. The dose response showed the same inverted U-shape reported in many behavioral studies following systemic injection of CBD in rodents [24, 25, 36, 37] and humans [38]. The $10 \mathrm{mg} / \mathrm{kg}$ I.P. dose stood out as being the most effective, corroborating the many studies in rodents employing this dose [24-26, 36]. Within $10 \mathrm{~min}$ of injection, there was increase in positive BOLD signal in the prefrontal cortex/olfactory system and negative BOLD signal in the brainstem/cerebellum, particularly in brains areas comprising the ARAS. The absence of BOLD signal change in brain areas between the rostral/caudal axis of the brain (e.g., hippocampus, sensorimotor cortices, thalamus, hypothalamus, amygdala, and basal ganglia) made this pattern of activation and deactivation especially intriguing. This is unlike anything reported in awake animal imaging following tests on numerous CNS active drugs [8-11,39-47]. Here we show the positive and negative changes in BOLD signal occur within $10 \mathrm{~min}$ of injection, and while CBD is known to rapidly penetrate the brain within seconds following systemic administration [48], its effects could be orchestrated easily by both peripheral and central targets. It should be noted that a pharmacokinetics study by Holzek et al. reported a much slower time course for brain penetrance following systemic CBD treatment [49].

\section{CBD targets}

The primary targets for systemic CBD are unknown. Possible candidates include the cannabinoid $\mathrm{CB} 1$ receptors $[50,51]$, serotonin $5 \mathrm{HT} 1 \mathrm{a}$ receptor, and the transient receptor potential vanilloid type 1 (TRPV1) [7, 52]. One important consequence of systemic CBD is the dramatic change in the CNS lipidome including increases in anandamide and related lipids that occurred in a NAPE-PLD dependent manner [22]. Do the CBD induced site-specific change in brain activity reported in our study match the distribution the putative targets noted above? CB1 receptors are localized to olfactory system, hippocampus, basal ganglia, cerebellum, and neocortex but very little in brainstem [53]. High densities of 5HT1a receptors are localized to prefrontal cortex, amygdala, hippocampus, and hypothalamus, while receptors are undetectable in the cerebellum and marginal in the brainstem $[54,55]$. TRPV1 is expressed throughout the CNS with the highest density of receptors localized to the hippocampus, amygdala, hypothalamus, prefrontal cortex, and cerebellar cortex, while the lowest levels are in the brainstem [56-58]. NAPE-PLD distribution as shown in Fig. 5 is highest in hippocampus, cerebellum, olfactory system, and site-specific areas of the thalamus, amygdala, and brainstem $[59,60]$. The distribution of NAPE-PLD seems to fit the activity pattern of CBD, specifically with respect 
to the ARAS. However, neither the distribution of CB1, 5HT1a, TRPV1, nor NAPE-PLD alone or together, can explain the absence of responsiveness of large parts of the brain to CBD or the polarization of BOLD signal. CBD has a complex pharmacology with activity at multiple targets beyond those discussed above (review see [7]). Given the promiscuity of $\mathrm{CBD}$, there is no obvious explanation for the pattern of BOLD signal change based on location of a single target in the brain.

\section{Autonomic arousal and stress}

The negative BOLD in brain areas that comprise the ARAS would suggest a decrease in brain activity and a reduction in autonomic arousal. Acute and chronic dosing of CBD in humans and animals has no appreciable effect on blood pressure, heart rate or blood flow [61]. However, CBD mediates the emotional and cardiovascular response to stress. CBD blunts the increased heart rate and blood pressure associated with the stress of forced immobilization $[26,62,63]$ and increase in blood pressure, heart rate and immobility behavior in response to fear associated with the memory of an aversive condition [64]. CBD reduces immobility and escape behavior in mice exposed to a wild snake [65], altering the innate fear and aversion to predation. Rats exposed to cats present with long-lasting anxiogenic behavior that can be reduced with CBD [66]. Thus, CBD can reduce the anxiety, fear and immobilization associated with stressful or life-threatening events.

\section{Speculation}

Interesting by its very nature, awake fMRI is a model of restraint stress, requiring the immobilization of the head to minimize artifacts. Acclimation is used to reduce the autonomic measures of stress [28], meaning the test subjects have a history of stress and adaptation. In additional, there is probably some emotional/physical stress associated with drug delivery during testing. The deactivation of the ARAS as interpreted by the increase in negative BOLD would be anticipated under these conditions and provide a neural target for $\mathrm{CBD}$ that would explain the reduction in autonomic and behavioral responses associated with anxious and potentially harmful environmental stimuli. Is the negative BOLD response to the ARAS unique to the acclimation process, i.e., is it an adaptation that has primed the lipidome to function under a new set of environmental pressures?

\section{Evolutionary significance}

Is there a neurobiological explanation in the evolution of animals that would favor the global pattern of deactivation and uncoupling of functional circuits observed in much of the brain while favoring activation and hyperconnectivity to the forebrain and olfactory system by the ARAS? CDB is most effective when given to patients or animals presenting with high anxiety and fear. Specifically, it can reduce heart rate and blood pressure during heighten sympathetic arousal but has little to no intrinsic effect on these autonomic measures under homeostatic conditions. CBD is acting on reactive neural circuitry-the brain's prewired, immediate response to threat. Freezing or behavioral arrest is a natural response to predator threat as a way of reducing detection. However, when the interaction becomes physical, the behavioral arrest can escalate into tonic immobility, an innate response of extreme physical inactivity [67]. This last chance to escape predation is commonly referred to as death feigning [68]. The immobility arises from descending neurons in the medullary, pontine reticular formation that suppress spinal motor neuron activity [69]. The neural circuitry of tonic immobility includes much of the ARAS described here [70-72], in addition to the PAG [73, 74], basolateral and central amygdala [75], and medial dorsal thalamus [76]. Treatment with CBD affects the BOLD signal and rsFC in all these areas. One of the more fascinating aspects of tonic immobility is continued sensory perception, i.e., animals feigning death can process sensory information and are aware of their environment $[72,77,78]$. The activation of the olfactory system by CBD would allow animals to continually survey their environment for the presence of the predator. The hypothesis that CBD could be affecting endocannabinoid signaling through NAPE-PLD is purely speculative but given the unique pattern of global brain activity caused by CBD treatment may warrant investigation and has far reaching implications. The neuropsychiatric trauma associated with life threatening experiences, e.g. PTSD, may crystalize around this phylogenetically old neural circuitry primal to survival [79]. Indeed, the evidence for $\mathrm{CBD}$ and endocannabinoid signaling playing a significant role in emotional regulation in neuropsychiatric disorders is growing [80].

\section{Limitations}

(1) These studies did not address sex difference in CBD responsivity. The previous study investigating CBD's effects on the brain lipidome were in female mice [22], so there is evidence that CBD has a significant effect on the brain within the time period; however, future studies will need to address if the changes in brain connectivity shown here in male mice are also measured in female mice. (2) Resting state functional connectivity was collected while rat were lightly anesthetized with isoflurane to minimize motion and physiological stress during "resting state" BOLD functional connectivity imaging (review see [81]). Anesthesia may reduce the magnitude 
of the BOLD signal but does not disrupt the connectivity as demonstrated across species and under different physiological conditions [82-86]. In this study the rsFC showed hyperconnectivity and hypoconnectivity that was consistent with the phMRI data. (3) There were no measures of NAPE-PLD activity in response to CBD challenge. These studies were not originally designed to test the involvement of NAPE-PLD.

\section{Summary}

phMRI in awake mice was used to assess the immediate dose-dependent effects of CBD on global brain activity. The pattern of brain activity was unique and unexpected, characterized by activation in the prefrontal cortex and deactivation in the brainstem/cerebellum, particularly in the ARAS. These data provide a novel framework to understand how CBD drives CNS changes that can be targeted for therapeutics. The putative target and mechanism of action is NAPE-PLD the enzyme responsible for the biosynthesis of lipid signaling molecules like anandamide.

\section{Supplementary Information}

The online version contains supplementary material available at https://doi. org/10.1186/s12967-021-02891-6.

Additional file 1. Supplementary Data.

\section{Acknowledgements}

Dr. Alex Makriyannis and the Center for Drug Discovery, Northeastern University for providing CBD.

\section{Authors' contributions \\ All of the authors have contributed substantially to the manuscript. All authors have read and agreed to the published version of the manuscript. Concept, drafting and interpretation-CFF, PK, AGH, HBB, ALL. Execution and analysis-AHS, AGO, PK, CFF, CTJ, HBB. All authors read and approved the final manuscript.}

\section{Funding}

Supported by DA047858, DA041229, CA200417 (AGH), DA041208 (HBB), DA024628 (CTJ), and a Grant Linking University Wide Expertise from the Indiana Clinical Translational Sciences Institute. Support for this study was also provided in part by the Larry P. Jones Distinguished Professorship Endowment through The University of Texas El Paso (BSC), NIH MIGMS 5R25GM069621-17 (RJO) and in part by a HHMI funded Inclusive Excellence Award to Northeastern University PI Ondrechen.

\section{Availability of data and materials}

All data can be accessed through a link to Mendeley. DOI to follow.

\section{Declarations}

Ethics approval and consent to participate

Not applicable.

\section{Consent for publication}

Yes.

\section{Competing interests}

Ferris has a financial interest in Animal Imaging Research, the company that makes the radiofrequency electronics and holders for animal imaging. Authors Kulkarni, Hohmann, Li, Sadaka, Ozuna, Ortiz, Cushing, Johnson, and Bradshaw have no biomedical financial interests or potential conflicts of interest.

\section{Author details}

${ }^{1}$ Center for Translational Neurolmaging, Northeastern University, Boston, MA, USA. ${ }^{2}$ Department of Biological Sciences, University of Texas At El Paso, El Paso, TX 79968, USA. ${ }^{3}$ Psychological and Brain Sciences, Program in Neuroscience, Indiana University, Bloomington, IN, USA. ${ }^{4}$ Gill Center for Biomolecular Science, Indiana University, Bloomington, IN, USA. ${ }^{5}$ Psychology and Pharmaceutical Sciences, Northeastern University, Boston, MA, USA. ${ }^{6}$ Department of Psychology, Northeastern University, $125 \mathrm{NI}$ Hall, 360 Huntington Ave, Boston, MA 02115-5000, USA.

Received: 17 February 2021 Accepted: 17 May 2021

Published online: 24 May 2021

\section{References}

1. Lee JLC, Bertoglio LJ, Guimaraes FS, Stevenson CW. Cannabidiol regulation of emotion and emotional memory processing: relevance for treating anxiety-related and substance abuse disorders. Br J Pharmacol. 2017;174:3242-56. https://doi.org/10.1111/bph.13724.PMC5595771.

2. Wright M, Di Ciano P, Brands B. Use of cannabidiol for the treatment of anxiety: a short synthesis of pre-clinical and clinical evidence. Cannabis Cannabinoid Res. 2020;5:191-6. https://doi.org/10.1089/can.2019.0052. PMC7480724.

3. Poleg S, Golubchik P, Offen D, Weizman A. Cannabidiol as a suggested candidate for treatment of autism spectrum disorder. Prog Neuropsychopharmacol Biol Psychiatry. 2019;89:90-6. https://doi.org/10.1016/j. pnpbp.2018.08.030.

4. Davies C, Bhattacharyya S. Cannabidiol as a potential treatment for psychosis. Ther Adv Psychopharmacol. 2019. https://doi.org/10.1177/20451 25319881916.PMC6843725.

5. Hindocha C, Cousijn J, Rall M, Bloomfield MAP. The effectiveness of cannabinoids in the treatment of posttraumatic stress disorder (PTSD): a systematic review. J Dual Diagn. 2020;16:120-39. https://doi.org/10.1080/ 15504263.2019.1652380.

6. Golub V, Reddy DS. Cannabidiol therapy for refractory epilepsy and seizure disorders. Adv Exp Med Biol. 2021;1264:93-110. https://doi.org/ 10.1007/978-3-030-57369-0_7.

7. McPartland JM, Duncan M, Di Marzo V, Pertwee RG. Are cannabidiol and Delta(9)-tetrahydrocannabivarin negative modulators of the endocannabinoid system? A systematic review. Br J Pharmacol. 2015;172:737-53. https://doi.org/10.1111/bph.12944.PMC4301686.

8. Brevard ME, Kulkarni P, King JA, Ferris CF. Imaging the neural substrates involved in the genesis of pentylenetetrazol-induced seizures. Epilepsia. 2006;47:745-54. https://doi.org/10.1111/j.1528-1167.2006.00502.x.

9. Ferris CF, Kulkarni P, Sullivan JM Jr, Harder JA, Messenger TL, Febo M. Pup suckling is more rewarding than cocaine: evidence from functional magnetic resonance imaging and three-dimensional computational analysis. J Neurosci. 2005;25:149-56. https://doi.org/10.1523/JNEUROSCI.3156-04. 2005.PMC6725197.

10. Madularu D, Yee JR, Kenkel WM, Moore KA, Kulkarni P, Shams WM, et al. Integration of neural networks activated by amphetamine in females with different estrogen levels: a functional imaging study in awake rats. Psychoneuroendocrinology. 2015;56:200-12. https://doi.org/10.1016/j. psyneuen.2015.02.022.

11. Moore K, Madularu D, Iriah S, Yee JR, Kulkarni P, Darcq E, et al. BOLD imaging in awake wild-type and mu-opioid receptor knock-out mice reveals on-target activation maps in response to oxycodone. Front Neurosci. 2016;10:471. https://doi.org/10.3389/fnins.2016.00471.PMC5094148.

12. Bhattacharyya S, Crippa JA, Allen P, Martin-Santos R, Borgwardt S, FusarPoli P, et al. Induction of psychosis by Delta9-tetrahydrocannabinol reflects modulation of prefrontal and striatal function during attentional salience processing. Arch Gen Psychiatry. 2012;69:27-36. https://doi.org/ 10.1001/archgenpsychiatry.2011.161. 
13. Bhattacharyya S, Falkenberg I, Martin-Santos R, Atakan Z, Crippa JA, Giampietro V, et al. Cannabinoid modulation of functional connectivity within regions processing attentional salience. Neuropsychopharmacology. 2015;40:1343-52. https://doi.org/10.1038/npp.2014.258.PMC43 97391.

14. Bloomfield MAP, Green SF, Hindocha C, Yamamori Y, Yim JLL, Jones APM, et al. The effects of acute cannabidiol on cerebral blood flow and its relationship to memory: An arterial spin labelling magnetic resonance imaging study. J Psychopharmacol. 2020;34:981-9. https://doi.org/10. 1177/0269881120936419.PMC7436497.

15. Fusar-Poli P, Crippa JA, Bhattacharyya S, Borgwardt SJ, Allen P, MartinSantos R, et al. Distinct effects of \{delta\}9-tetrahydrocannabinol and cannabidiol on neural activation during emotional processing. Arch Gen Psychiatry. 2009;66:95-105. https://doi.org/10.1001/archgenpsychiatry. 2008.519.

16. Grimm O, Loffler M, Kamping S, Hartmann A, Rohleder C, Leweke M, et al. Probing the endocannabinoid system in healthy volunteers: cannabidiol alters fronto-striatal resting-state connectivity. Eur Neuropsychopharmacol. 2018;28:841-9. https://doi.org/10.1016/j.euroneuro.2018.04.004.

17. Nenert R, Allendorfer JB, Bebin EM, Gaston TE, Grayson LE, Houston JT, et al. Cannabidiol normalizes resting-state functional connectivity in treatment-resistant epilepsy. Epilepsy Behav. 2020;1 12:107297. https:// doi.org/10.1016/j.yebeh.2020.107297.

18. O'Neill A, Wilson R, Blest-Hopley G, Annibale L, Colizzi M, Brammer $M$, et al. Normalization of mediotemporal and prefrontal activity, and mediotemporal-striatal connectivity, may underlie antipsychotic effects of cannabidiol in psychosis. Psychol Med. 2020. https://doi.org/10.1017/ S0033291719003519.

19. Winton-Brown TT, Allen P, Bhattacharyya S, Borgwardt SJ, Fusar-Poli P, Crippa JA, et al. Modulation of auditory and visual processing by delta9-tetrahydrocannabinol and cannabidiol: an FMRI study. Neuropsychopharmacology. 2011;36:1340-8. https://doi.org/10.1038/npp.2011.17. PMC3096803.

20. Borsook D, Becerra L, Hargreaves R. A role for fMRI in optimizing CNS drug development. Nat Rev Drug Discov. 2006;5:411-24. https://doi.org/10. 1038/nrd2027.

21. Haensel JX, Spain A, Martin C. A systematic review of physiological methods in rodent pharmacological MRI studies. Psychopharmacology. 2015;232:489-99. https://doi.org/10.1007/s00213-014-3855-0.PMC4302233.

22. Leishman E, Manchanda M, Thelen R, Miller S, Mackie K, Bradshaw HB. Cannabidiol's Upregulation of $\mathrm{N}$-acyl ethanolamines in the central nervous system requires $\mathrm{N}$-acyl phosphatidyl ethanolamine-specific phospholipase D. Cannabis Cannabinoid Res. 2018;3:228-41. https://doi. org/10.1089/can.2018.0031.PMC6277981.

23. Kilkenny C, Browne W, Cuthill IC, Emerson M, Altman DG, Group NCRRGW. Animal research: reporting in vivo experiments: the ARRIVE guidelines. $\mathrm{Br}$ J Pharmacol. 2010;160:1577-9. https://doi.org/10.1111/j.1476-5381.2010. 00872.x.PMC2936830.

24. Stern CA, Gazarini L, Takahashi RN, Guimaraes FS, Bertoglio LJ. On disruption of fear memory by reconsolidation blockade: evidence from cannabidiol treatment. Neuropsychopharmacology. 2012;37:2132-42. https://doi.org/10.1038/npp.2012.63.PMC3398715.

25. Stern CAJ, da Silva TR, Raymundi AM, de Souza CP, Hiroaki-Sato VA, Kato L, et al. Cannabidiol disrupts the consolidation of specific and generalized fear memories via dorsal hippocampus CB1 and CB2 receptors. Neuropharmacology. 2017;125:220-30. https://doi.org/10.1016/j.neuropharm.2017.07.024.

26. Resstel LB, Tavares RF, Lisboa SF, Joca SR, Correa FM, Guimaraes FS. 5-HT1A receptors are involved in the cannabidiol-induced attenuation of behavioural and cardiovascular responses to acute restraint stress in rats. Br J Pharmacol. 2009;156:181-8. https://doi.org/10.1111/j.1476-5381.2008. 00046.X.PMC2697769.

27. Ferris CF, Kulkarni P, Toddes S, Yee J, Kenkel W, Nedelman M. Studies on the Q175 Knock-in model of Huntington's disease using functional imaging in awake mice: evidence of olfactory dysfunction. Front Neurol. 2014;5:94. https://doi.org/10.3389/fneur.2014.00094.PMC4074991.

28. King JA, Garelick TS, Brevard ME, Chen W, Messenger TL, Duong TQ, et al. Procedure for minimizing stress for fMRI studies in conscious rats. J Neurosci Methods. 2005;148:154-60.

29. Ferris CF, Smerkers B, Kulkarni P, Caffrey M, Afacan O, Toddes S, et al. Functional magnetic resonance imaging in awake animals. Rev Neurosci. 2011;22:665-74. https://doi.org/10.1515/RNS.2011.050.
30. Ferris CF, Yee JR, Kenkel WM, Dumais KM, Moore K, Veenema AH, et al. Distinct BOLD activation profiles following central and peripheral oxytocin administration in awake rats. Front Behav Neurosci. 2015;9:245. https:// doi.org/10.3389/fnbeh.2015.00245.4585275.

31. Bastian M, Heymann S, Jacomy M. Gephi: an open source software for exploring and manipulating networks. In: International AAAI conference on weblogs and social media; 2009

32. Institute A. Allen mouse brain atals. In: sagittal N-RB, editor; 2018.

33. Saper CB. Central autonomic system. In: Paxinos $G$, editor. The rat nervous system. New York: Academic Press; 1995. p. 107-35.

34. Hussain Z, Uyama T, Tsuboi K, Ueda N. Mammalian enzymes responsible for the biosynthesis of $\mathrm{N}$-acylethanolamines. Biochim Biophys Acta Mol Cell Biol Lipids. 2017;1862:1546-61. https://doi.org/10.1016/j.bbalip.2017. 08.006 .

35. Crippa JA, Zuardi AW, Garrido GE, Wichert-Ana L, Guarnieri R, Ferrari L, et al. Effects of cannabidiol (CBD) on regional cerebral blood flow. Neuropsychopharmacology. 2004;29:417-26. https://doi.org/10.1038/sj.npp. 1300340.

36. Guimaraes FS, Chiaretti TM, Graeff FG, Zuardi AW. Antianxiety effect of cannabidiol in the elevated plus-maze. Psychopharmacology. 1990;100:558-9. https://doi.org/10.1007/BF02244012.

37. Levin R, Peres FF, Almeida V, Calzavara MB, Zuardi AW, Hallak JE, et al. Effects of cannabinoid drugs on the deficit of prepulse inhibition of startle in an animal model of schizophrenia: the SHR strain. Front Pharmacol. 2014;5:10. https://doi.org/10.3389/fphar.2014.00010.PMC3915876.

38. Zuardi AW, Rodrigues NP, Silva AL, Bernardo SA, Hallak JEC, Guimaraes FS, et al. Inverted U-shaped dose-response curve of the anxiolytic effect of cannabidiol during public speaking in real life. Front Pharmacol. 2017:8:259. https://doi.org/10.3389/fphar.2017.00259.PMC5425583.

39. Brevard ME, Meyer JS, Harder JA, Ferris CF. Imaging brain activity in conscious monkeys following oral MDMA ("ecstasy"). Magn Reson Imaging. 2006;24:707-14. https://doi.org/10.1016/j.mri.2006.03.010.

40. Ferris CF, Stolberg T. Imaging the immediate non-genomic effects of stress hormone on brain activity. Psychoneuroendocrinology. 2010;35:514. https://doi.org/10.1016/j.psyneuen.2009.09.003.

41. Ferris C. Using awake animal imaging to finger print drugs for CNS liability: risk for suicide? In: Cannon K, Hudzik T, editors. Suicide phenomenology and neurobiology. New York: Springer Press; 2014. p. 261-72.

42. Febo M, Ferris CF. Oxytocin and vasopressin modulation of the neural correlates of motivation and emotion: results from functional MRI studies in awake rats. Brain Res. 2014;1580:8-21. https://doi.org/10.1016/j.brainres. 2014.01.019.PMC4712919.

43. Madularu D, Kulkarni P, Yee JR, Kenkel WM, Shams WM, Ferris CF, et al. High estrogen and chronic haloperidol lead to greater amphetamineinduced BOLD activation in awake, amphetamine-sensitized female rats. Horm Behav. 2016;82:56-63. https://doi.org/10.1016/j.yhbeh.2016.04.007.

44. Madularu D, Yee JR, Kulkarni P, Ferris CF. System-specific activity in response to Delta(9) -tetrahydrocannabinol: a functional magnetic resonance imaging study in awake male rats. Eur J Neurosci. 2017;46:2893900. https://doi.org/10.1111/ejn.13754.

45. Farra YM, Eden MJ, Coleman JR, Kulkarni P, Ferris CF, Oakes JM, et al. Acute neuroradiological, behavioral, and physiological effects of noseonly exposure to vaporized cannabis in C57BL/6 mice. Inhalat Toxicol. 2020;32:200-17. https://doi.org/10.1080/08958378.2020.1767237.

46. Iriah SC, Trivedi M, Kenkel W, Grant SE, Moore K, Yee JR, et al. Oxycodone exposure: a magnetic resonance imaging study in response to acute and chronic oxycodone treatment in rats. Neuroscience. 2019;398:88-101. https://doi.org/10.1016/j.neuroscience.2018.11.042.

47. Ferris CF, Kulkarni P, Yee JR, Nedelman M, de Jong IEM. The serotonin receptor 6 antagonist idalopirdine and acetylcholinesterase inhibitor donepezil have synergistic effects on brain activity-A functional MRI study in the awake rat. Front Pharmacol. 2017;8:279. https://doi.org/10. 3389/fphar.2017.00279.PMC5467007.

48. Alozie SO, Martin BR, Harris LS, Dewey WL. 3H-delta 9-Tetrahydrocannabinol, $3 \mathrm{H}$-cannabinol and $3 \mathrm{H}$-cannabidiol: penetration and regional distribution in rat brain. Pharmacol Biochem Behav. 1980;12:217-21. https://doi.org/10.1016/0091-3057(80)90359-7.

49. Hlozek T, Uttl L, Kaderabek L, Balikova M, Lhotkova E, Horsley RR, et al. Pharmacokinetic and behavioural profile of THC, CBD, and THC+CBD combination after pulmonary, oral, and subcutaneous administration in rats and confirmation of conversion in vivo of CBD to THC. Eur 
Neuropsychopharmacol. 2017;27:1223-37. https://doi.org/10.1016/j. euroneuro.2017.10.037.

50. Laprairie RB, Bagher AM, Kelly ME, Denovan-Wright EM. Cannabidiol is a negative allosteric modulator of the cannabinoid CB1 receptor. Br J Pharmacol. 2015;172:4790-805. https://doi.org/10.1111/bph.13250.PMC4621983.

51. Straiker A, Dvorakova M, Zimmowitch A, Mackie K. Cannabidiol inhibits endocannabinoid signaling in autaptic hippocampal neurons. Mol Pharmacol. 2018;94:743-8. https://doi.org/10.1124/mol.118.111864.PMC5988021.

52. Lisboa SF, Vila-Verde C, Rosa J, Uliana DL, Stern CAJ, Bertoglio LJ, et al. Tempering aversive/traumatic memories with cannabinoids: a review of evidence from animal and human studies. Psychopharmacology. 2019;236:201-26. https://doi.org/10.1007/s00213-018-5127-x.

53. Egertova M, Elphick MR. Localisation of cannabinoid receptors in the rat brain using antibodies to the intracellular C-terminal tail of CB. J Comp Neurol. 2000;422:159-71. https://doi.org/10.1002/(sici)1096-9861(20000626) 422:2\%3c159::aid-cne1\%3e3.0.co;2-1.

54. Chalmers DT, Watson SJ. Comparative anatomical distribution of 5-HT1A receptor mRNA and 5-HT1A binding in rat brain-a combined in situ hybridisation/in vitro receptor autoradiographic study. Brain Res. 1991;561:51-60. https://doi.org/10.1016/0006-8993(91)90748-k.

55. Pazos A, Palacios JM. Quantitative autoradiographic mapping of serotonin receptors in the rat brain. I. Serotonin-1 receptors. Brain Res. 1985;346:20530. https://doi.org/10.1016/0006-8993(85)90856-X.

56. Toth A, Boczan J, Kedei N, Lizanecz E, Bagi Z, Papp Z, et al. Expression and distribution of vanilloid receptor 1 (TRPV1) in the adult rat brain. Brain Res Mol Brain Res. 2005;135:162-8. https://doi.org/10.1016/j.molbrainres.2004. 12.003.

57. Acs G, Palkovits M, Blumberg PM. Specific binding of [3H]resiniferatoxin by human and rat preoptic area, locus ceruleus, medial hypothalamus, reticular formation and ventral thalamus membrane preparations. Life Sci. 1996:59:1899-908. https://doi.org/10.1016/s0024-3205(96)00537-1.

58. Roberts JC, Davis JB, Benham CD. [3H]Resiniferatoxin autoradiography in the CNS of wild-type and TRPV1 null mice defines TRPV1 (VR-1) protein distribution. Brain Res. 2004;995:176-83. https://doi.org/10.1016/j.brainres. 2003.10.001.

59. Egertova M, Simon GM, Cravatt BF, Elphick MR. Localization of N-acyl phosphatidylethanolamine phospholipase D (NAPE-PLD) expression in mouse brain: A new perspective on $\mathrm{N}$-acylethanolamines as neural signaling molecules. J Comp Neurol. 2008;506:604-15. https://doi.org/10.1002/cne. 21568.

60. Morishita J, Okamoto Y, Tsuboi K, Ueno M, Sakamoto H, Maekawa N, et al. Regional distribution and age-dependent expression of $\mathrm{N}$-acylphosphatidylethanolamine-hydrolyzing phospholipase D in rat brain. J Neurochem. 2005;94:753-62. https://doi.org/10.1111/j.1471-4159.2005.03234.x.

61. Sultan SR, Millar SA, England TJ, O'Sullivan SE. A systematic review and metaanalysis of the haemodynamic effects of cannabidiol. Front Pharmacol. 2017:8:81. https://doi.org/10.3389/fphar.2017.00081.PMC5323388.

62. Granjeiro EM, Gomes FV, Guimaraes FS, Correa FM, Resstel LB. Effects of intracisternal administration of cannabidiol on the cardiovascular and behavioral responses to acute restraint stress. Pharmacol Biochem Behav. 2011:99:743-8. https://doi.org/10.1016/j.pbb.2011.06.027.

63. Gomes FV, Reis DG, Alves FH, Correa FM, Guimaraes FS, Resstel LB. Cannabidiol injected into the bed nucleus of the stria terminalis reduces the expression of contextual fear conditioning via 5-HT1A receptors. J Psychopharmacol. 2012;26:104-13. https://doi.org/10.1177/0269881110389095.

64. Resstel LB, Joca SR, Moreira FA, Correa FM, Guimaraes FS. Effects of cannabidiol and diazepam on behavioral and cardiovascular responses induced by contextual conditioned fear in rats. Behav Brain Res. 2006;172:294-8. https://doi.org/10.1016/j.bbr.2006.05.016.

65. Uribe-Marino A, Francisco A, Castiblanco-Urbina MA, Twardowschy A, Salgado-Rohner CJ, Crippa JA, et al. Anti-aversive effects of cannabidiol on innate fear-induced behaviors evoked by an ethological model of panic attacks based on a prey vs the wild snake Epicrates cenchria crassus confrontation paradigm. Neuropsychopharmacology. 2012;37:412-21. https:// doi.org/10.1038/npp.2011.188.PMC3242302.

66. Campos AC, Ferreira FR, Guimaraes FS. Cannabidiol blocks long-lasting behavioral consequences of predator threat stress: possible involvement of 5HT1A receptors. J Psychiatr Res. 2012;46:1501-10. https://doi.org/10.1016/j. jpsychires.2012.08.012.

67. Bovin MJ, Jager-Hyman S, Gold SD, Marx BP, Sloan DM. Tonic immobility mediates the influence of peritraumatic fear and perceived inescapability on posttraumatic stress symptom severity among sexual assault survivors. J Trauma Stress. 2008;21:402-9. https://doi.org/10.1002/jts.20354.

68. Honma A, Oku S, Nishida T. Adaptive significance of death feigning posture as a specialized inducible defence against gape-limited predators. Proc Biol Sci R Soc. 2006;273:1631-6. https://doi.org/10.1098/rspb.2006.3501.PMC16 34928.

69. Klemm WR. Neurophysiologic studies of the immobility reflex ("animal hypnosis"). Neurosci Res (NY). 1971;4:165-212.

70. Menescal-de-Oliveira L, Hoffmann A. The parabrachial region as a possible region modulating simultaneously pain and tonic immobility. Behav Brain Res. 1993;56:127-32. https://doi.org/10.1016/0166-4328(93)90030-t.

71. Klemm WR. Mechanisms of the immobility reflex ('animal hypnosis'). II. EEG and multiple unit correlates in the brain stem. Comm Behav Biol. 1969:3:43-52.

72. Klemm WR. EEG and multiple-unit activity in limbic and motor systems during movement and immobility. Physiol Behav. 1971;7:337-43. https://doi. org/10.1016/0031-9384(71)90311-8.

73. Monassi CR, Leite-Panissi CR, Menescal-de-Oliveira L. Ventrolateral periaqueductal gray matter and the control of tonic immobility. Brain Res Bull. 1999:50:201-8. https://doi.org/10.1016/s0361-9230(99)00192-6.

74. Vieira EB, Menescal-de-Oliveira L, Leite-Panissi CR. Functional mapping of the periaqueductal gray matter involved in organizing tonic immobility behavior in guinea pigs. Behav Brain Res. 2011;216:94-9. https://doi.org/10. 1016/j.bbr.2010.07.013.

75. Spinieli RL, Leite-Panissi CRA. Similar effect of CRF1 and CRF2 receptor in the basolateral or central nuclei of the amygdala on tonic immobility behavior. Brain Res Bull. 2018;137:187-96. https://doi.org/10.1016/j.brain resbull.2017.12.006.

76. Giber K, Diana MA, Plattner V, Dugue GP, Bokor H, Rousseau CV, et al. A subcortical inhibitory signal for behavioral arrest in the thalamus. Nat Neurosci. 2015:18:562-8. https://doi.org/10.1038/nn.3951.PMC4885661.

77. Gallup GG Jr, Boren JL, Suarez SD, Wallnau LB, Gagliardi GJ. Evidence for the integrity of central processing during tonic immobility. Physiol Behav. 1980;25:189-94. https://doi.org/10.1016/0031-9384(80)90206-1.

78. Klemm WR. Evoked responses in brain motor areas during the immobility reflex ("animal hypnosis"). Physiol Behav. 1971;6:137-44. https://doi.org/10. 1016/0031-9384(71)90081-3.

79. Cantor C. Post-traumatic stress disorder: evolutionary perspectives. Aust N Z J Psychiatry. 2009;43:1038-48. https://doi.org/10.3109/00048670903270407.

80. Hill MN, Campolongo P, Yehuda R, Patel S. Integrating endocannabinoid signaling and cannabinoids into the biology and treatment of posttraumatic stress disorder. Neuropsychopharmacology. 2018:43:80-102. https:// doi.org/10.1038/npp.2017.162.PMC5719095.

81. Gorges M, Roselli F, Muller HP, Ludolph AC, Rasche V, Kassubek J. Functional connectivity mapping in the animal model: principles and applications of resting-state fMRI. Front Neurol. 2017:8:200. https://doi.org/10.3389/fneur. 2017.00200 .5423907$.

82. Liang Z, King J, Zhang N. Intrinsic organization of the anesthetized brain. J Neurosci. 2012;32:10183-91. https://doi.org/10.1523/JNEUROSCl.1020-12. 2012.PMC3422560.

83. Vincent JL, Patel GH, Fox MD, Snyder AZ, Baker JT, Van Essen DC, et al. Intrinsic functional architecture in the anaesthetized monkey brain. Nature. 2007:447:83-6. https://doi.org/10.1038/nature05758.

84. Gozzi A, Schwarz AJ. Large-scale functional connectivity networks in the rodent brain. Neuroimage. 2016;127:496-509. https://doi.org/10.1016/j. neuroimage.2015.12.017

85. Guilfoyle DN, Gerum SV, Sanchez JL, Balla A, Sershen H, Javitt DC, et al. Functional connectivity fMRl in mouse brain at 7 T using isoflurane. J Neurosci Methods. 2013;214:144-8. https://doi.org/10.1016/j.jneumeth.2013.01.019. 3644382.

86. Jonckers E, Delgado y Palacios R, Shah D, Guglielmetti C, Verhoye M, Van der Linden A, . Different anesthesia regimes modulate the functional connectivity outcome in mice. Magn Reson Med. 2014;72:1103-12. https://doi.org/10. 1002/mrm.24990.

\section{Publisher's Note}

Springer Nature remains neutral with regard to jurisdictional claims in published maps and institutional affiliations. 